Revista Iberoamericana, Vol. LXVIII, Núm. 200, Julio-Septiembre 2002, 503-517

\title{
EL INSTITUTO INTERNACIONAL DE LITERATURA IBEROAMERICANA Y LA REVISTA IBEROAMERICANA: BREVE RELATO DE UNA YA LARGA HISTORIA
}

\author{
POR \\ Gerald Martin \\ Presidente del IILI \\ Universidad de Pittsburgh
}

En agosto de 1938, a seis meses del final de la Guerra Civil Española y un año escaso antes del comienzo de la Segunda Guerra Mundial, un pequeño grupo de profesores universitarios de ambas Américas organizó un congreso sobre literatura iberoamericana que se celebró en la Universidad Nacional de México. Al final de la reunión declararon la creación de dos agencias nuevas para la promoción y propagación de la literatura y la crítica literaria latinoamericanas: el Instituto Internacional de Literatura Iberoamericana (IILI), que seguiría organizando congresos universitarios y la publicación de las “actas” correspondientes, y su órgano académico, la Revista Iberoamericana $(R I)$. Después de sesenta y cuatro años, treinta y cuatro congresos (en realidad, cuarenta, pues a veces ha habido dos "sesiones” por año) y doscientos números, contra todo lo que se podría haber profetizado, ambas entidades siguen tan campantes que decidimos marcar esta trayectoria sorprendente con un número especial en el que, finalmente, el Instituto y la Revista celebrarán modestamente su propia historia. ${ }^{1}$ Por eso este número 200 es una especie de resumen histórico o compendio antológico: significa un momento de descanso para sus editores, un regalo para sus socios (para leer, quizás, en vacaciones) y está dedicado a todos los que han contribuido a las dos instituciones entre 1938 y 2002. Este breve relato introductorio, bastante impresionista e incompleto, va acompañado por una extensiva cronología del desarrollo del IILI y la RI.

Como es natural, no compartimos necesariamente las ideas y posturas expresadas en los artículos y notas aquí reunidos. Nuestros criterios han sido la representatividad, la variedad y la brevedad, criterios a veces mutuamente excluyentes. Y no es necesario decir que cuando es cuestión de escoger unos cincuenta ensayos, notas y editoriales entre más

\footnotetext{
${ }^{1}$ Centenares de ensayos antologizables eran sencillamente demasiado largos para nuestros propósitos, por ejemplo (escogidos al azar): Pedro Salinas, “El cisne y el búho”, nro. 3, abril 1940, pp. 55-77; Juan José Arrom, "La poesía afro-cubana”, nro. 8, febrero 1942, pp. 379-411; José Antonio Portuondo, "El contenido político y social de las obras de José Antonio Ramos”, nro. 12, junio 1947, pp. 215-50; Martha E. Allen, "Dos estilos de novela: Marta Brunet y María Luisa Bombal”, no.35, diciembre 1952, pp. 63-92; Nelson Osorio, "Para una caracterización histórica del vanguardismo literario hispano-americano”, no.114-115, enero-junio 1981, pp. 227-54; Jacques Gilard, “El grupo de Barranquilla”, nro. 128-129, julio-diciembre 1984, pp. 905-35; Carlos Monsiváis, "No con un sollozo, sino entre disparos. (Nota sobre cultura mexicana 1910-1968)”, nro. 148-149, juliodiciembre 1989, pp. 715-35; etc., etc., etc.
} 
de cuatro mil, la arbitrariedad tiene algo que ver con el resultado. ${ }^{2}$ Aun así, los lectores instruidos divisarán posiblemente alguna lógica arquitectónica vacilante entre las vagas neblinas de nuestro pequeño laberinto. De todas formas, nuestra antología es una historia telescópica de la Revista, de la crítica literaria latinoamericana, y, más oscuramente, de los estudios latinoamericanos y de la misma América Latina durante el período que nos toca. Si esta aseveración puede parecer ambiciosa, habría que confesar que incluso estas cuatro historias parciales y vagas son más parciales y vagas de lo que habríamos querido debido a nuestras limitaciones de tiempo y de recursos, por no hablar de las limitaciones propias. Para hacer bien lo que nos propusimos, sería necesario un trabajo de años, no de meses; pero es por eso, sin duda, que se ha hecho tan poco hasta ahora. Con todo, esperamos que otros completarán, algún día, el trabajo iniciado aquí — por lo menos antes del centenario del IILI.

Detrás de la Revista y sus editores están siempre el Instituto, sus directores, sus congresos, y sus socios. Por eso decidimos que también sería útil incluir un artículo de Alfredo Roggiano explicando su propia relación con ambas entidades; un discurso que Rómulo Gallegos leyó frente al cuarto congreso del IILI pocos meses después de haber sido destituido de la presidencia de Venezuela por los militares; un poema dedicado a Rubén Darío que Pablo Neruda envió al XIII congreso; un ensayo un tanto periodístico que Emir Rodríguez Monegal, tan importante en la trayectoria de la Revista entre 1969 y 1986, publicó en Mundo Nuevo en 1967, en el que describe cómo es un Congreso del IILI y cómo se relaciona con su contexto sociocultural — en este caso venezolano- y con su contexto literario - en este caso el triunfo de Vargas Llosa con el Premio Gallegos y la primera aparición pública de García Márquez después del éxito de Cien años de soledad en Buenos Aires; $y$, finalmente, algunas notas necrológicas de personalidades inseparables de la historia y los logros del IILI, notas que también dan una visión impresionista de una época ya desaparecida del hispanoamericanismo norteamericano (son especialmente iluminadoras las notas escritas por el mismo Alfredo Roggiano).

La Revista ha tenido tres épocas: la de la Universidad Nacional de México, 19381956 (la menos conocida y apreciada; por eso le dedicamos más atención aquí); la de Alfredo Roggiano, Iowa y Pittsburgh, 1956-1991, completada por Keith McDuffie, 19911996; y la de Mabel Moraña, Pittsburgh, desde 1996 (aunque, en cierto sentido, desde 1993). Y es curioso constatar que desde nuestra perspectiva momentánea — ¿instantánea?en el año 2002 se divisa una extraña simetría en esta trayectoria. La época de Roggiano, la mejor conocida, consiguió, sin la menor duda, una consolidación del estatuto estrictamente

\footnotetext{
${ }^{2}$ Se han publicado algunos — pocos- estudios sobre la historia de la RI. Alfredo A. Roggiano habló en el 23o Congreso (Madrid, 1984) de la trayectoria de la RI, ponencia reproducida en las Actas ("La RI, Organo del IILI”) y también en este número. En 1990, Sonia Mora publicó en Hispania una breve entrevista con Roggiano en la que éste explicó cómo había tratado de evitar el faccionalismo para que la revista tuviera un espíritu "ecléctico, cosmopolita, integral y realmente internacional" (Hispania 73, septiembre 1990, pp. 63-65). También en 1990, Samuel Gordon, alumno de Roggiano, escribió un artículo, “Alfredo A. Roggiano, Director de la RI” (Actas del XXIX Congreso del IILI, PPU, Universitat de Barcelona, 1994, tomo I, pp. 89-107), para marcar los 150 números de la revista y, tal como sucedieron las cosas, para marcar la muerte de Roggiano, con especial énfasis en su contribución a la "creación literaria y la canonización crítica”.
} 
literario y académico de la revista-es la época de la literatura iberoamericana y de la crítica literaria iberoamericana en sentido estricto, académico, si bien la adhesión de Emir Rodríguez Monegal entre 1969 y 1986 añadió una dimensión un poco más "mundana" (comercial, editorial, publicitaria) a la empresa. Pero antes y después de Roggiano se percibe otro fenómeno: ambas son épocas en que la "crítica literaria” no es suficiente en sí para el estudio de la literatura (mejor dicho, la literatura en sí no es adecuada como concepto crítico). Entre 1938 y 1956, en una primera época de acercamiento supuestamente constructivo entre Iberoamérica y Estados Unidos (Roosevelt, "el buen vecino”, la alianza en la guerra, la OEA), lo que la Revista ofrece es una mezcla de crítica literaria, "pensamiento latinoamericano” y reflexiones sobre la identidad latinoamericana y las relaciones interamericanas. Y después de Roggiano, a partir de 1992, aproximadamente, en otra época de acelerada interacción entre Iberoamérica y Estados Unidos, bajo la sombra de la "globalización” "posmoderna”, la Revista ofrece una amalgama deliberadamente híbrida de crítica literaria (especialmente “teoría”), “estudios culturales” y nuevas reflexiones sobre la identidad (ahora "multicultural”) latinoamericana, interamericana e incluso intra-norteamericana (la identidad y cultura de los llamados "latinos” en Estados Unidos).

\section{LA PRIMERA ÉPOCA (“MeXICANA”) 1938-1955}

Ya mencionamos que el IILI se fundó en la Ciudad de México en agosto de 1938. El panorama internacional no podría haber sido más sombrío. En marzo, el presidente Lázaro Cárdenas había nacionalizado el petróleo mexicano, a pesar de la política del Buen Vecino promovida por Roosevelt, a partir de su primera inauguración en marzo de 1933. La Guerra Civil Española terminaría a fines de marzo de 1939 y la Segunda Guerra Mundial empezaría a comienzos de septiembre de 1939; Estados Unidos entraría en la guerra en diciembre de 1941.

Según la memoria histórica —o quizás "literaria”, y aun “folclórica” — del IILI, su génesis como institución estuvo en una conversación entre Pedro Henríquez Ureña, Alfonso Reyes y, tal vez, Manuel Pedro González. De todas formas, a fines de 1937 González llevó la propuesta a Julio Jiménez Rueda y Francisco Monterde, profesores de la Universidad Nacional (después Autónoma) de México, quienes organizaron el primer congreso en agosto de 1938. González (1893-1974), el primer presidente del Instituto, se distanció gradualmente de la organización después de una serie de conflictos (ver nota necrológica de Alfredo Roggiano reproducida en este número), pero Jiménez Rueda (1896-1960) y Monterde (1894-1985), por no decir la UNAM, se mantuvieron fieles al IILI. Jiménez Rueda, por ejemplo, asistió a cada uno de los primeros siete congresos. También fueron cruciales la intervención de Raimundo Lazo (1904-1976), organizador del congreso habanero de 1949, y la cooperación asidua de Mariano Picón Salas (19011965). Colaboraron con ellos un pequeño grupo de profesores latinoamericanos radicados en Estados Unidos, especialmente el chileno Arturo Torres-Rioseco (1897-1971) y el colombiano Carlos García-Prada (1898-), pero también José A. Balseiro (1900-), Luis Monguió, Andrés Iduarte (1907-), Enrique Anderson Imbert (1910-2000) y Fernando 
Alegría (1918-), una generación de críticos que pertenecían a la generación de escritores como Borges, Asturias, Carpentier, Neruda y Paz. Este grupo de latinoamericanos formaba el puente entre las universidades de América Latina y los latinoamericanistas norteamericanos como Sturgess E. Leavitt (1888-), John E. Englekirk (1905-1983), Erwin K. Mapes (1884-1961), John A. Crow, Irving A. Leonard, John T. Reid, Albert R. Lopes y Jefferson Rea Spell, entre muchos otros.

En su discurso inaugural dirigido al del primer congreso, el presidente del mismo, Julio Jiménez Rueda, declaró que, “de todas las manifestaciones de la cultura de Iberoamérica, la literatura es la que ha llegado a ser más conocida y apreciada en el mundo. Los poetas desde el siglo pasado, los novelistas en el presente, son leídos y comentados ya en su lengua original, ya en las traducciones que por fortuna se multiplican más cada día” ${ }^{3}$ Es una percepción que volvería a afirmarse en los años 60, en otra época decisiva de la Revista.

En el prefacio a la Memoria del Primer Congreso, publicada dos años después, Manuel Pedro González precisa que el propósito fundamental del IILI es "luchar por el mejoramiento de las relaciones culturales entre los países iberos de América así como entre éstos y la América anglosajona” y “estudiar los medios de mejorar la técnica de la enseñanza de nuestra literatura y buscar el procedimiento más adecuado y eficaz para divulgar su conocimiento fuera de los respectivos países en que se produce” (xi). Y añade: "El principio básico que orientó la labor del Congreso podría formularse así: La cultura es un campo neutro, con jurisdicción y fuero propios y con una esfera de acción universal y sin fronteras" (xi).

Esta ilusión feliz o mentira piadosa ha servido muy bien a los intereses del IILI y sus miembros: una parte importante de la misión del IILI ha sido, y sigue siendo, sin duda, la diplomacia cultural y académica. El Instituto ha representado, siempre según el prefacio de González, “el primer esfuerzo continental organizado que en América se realiza para beneficiar el estudio, la investigación y el mejor conocimiento recíproco de las diversas literaturas que actualmente se producen en la América ibera”. Y González enfatiza:

Esta Revista, como habrá podido verse en sus primeras entregas, aspira a ser índice y a la vez aglutinante de la literatura americana, incluyendo la del Brasil. No representa esta Revista a ningún país en particular ni a ningún grupo o modalidad especial, sino que está al servicio de la literatura iberoamericana en general y acoge gustosamente todas sus manifestaciones e invita a colaborar en sus páginas a todos los intelectuales americanos que por estos temas se preocupan seriamente. El espíritu de la Revista, como el del Instituto y los Congresos, es amplísimo y estetizado en la leyenda del sello oficial: A la fraternidad por la cultura”. (xii)

En los años cuarenta, la $R I$ se ocupaba predominantemente de la literatura y los escritores anteriores a la década del veinte. A pesar de que muchos de sus colaboradores eran no solamente profesores sino también poetas, periodistas y pensadores, sólo hacia fines de los cincuenta empezaría la revista a dedicar su atención a los narradores más o

\footnotetext{
${ }^{3}$ Memoria del Primer Congreso, ed. Francisco Monterde (Universidad Nacional de México, 1940),
} p.18. 
menos contemporáneos. Sería interesante trazar esta evolución lenta pero significativa, como también las inevitables limitaciones y contradicciones ideológicas de las primeras décadas, pero nos ha parecido una tarea que más bien incumbe a otros observadores. ${ }^{4}$

Algo que sí podemos mencionar, a pesar de la referencia permanente a la literatura “iberoamericana”, es la misión latinoamericana de las dos entidades. A diferencia de otras asociaciones o revistas, a nuestras dos instituciones les interesa, no España, no Francia, ni siquiera Estados Unidos (después del panamericanismo un poco tibio y siempre ambivalente de los primeros años, animado casi exclusivamente por Carlos García-Prada), sino América Latina, con todos sus nombres - Latinoamérica, Iberoamérica, Indoamérica, Hispanoamérica-y-Brasil, América Hispana, América Hispánica, etc. Es significativo que la Organización de Estados Americanos, fundada en abril de 1948, casi nunca se menciona en la páginas de la $R I$, mientras que la Unesco aparece en ellas con cierta frecuencia. Se trata entonces de un instituto globalmente "internacional” — de allí su nombre - antes que panamericano, en el que latinomericanos y norteamericanos colaboran para sistematizar e institucionalizar el estudio de la literatura latinomericana. ${ }^{5}$

Lo que más sorprende de estas dos entidades, al contemplarlas desde la actualidad, es la extraordinaria continuidad a través del tiempo. La primera asamblea determinó que habría una Mesa Directiva compuesta de un presidente, dos vicepresidentes, un secretario, un tesorero y siete vocales; la revista tendría, en primera instancia, cuatro editores, entre ellos, un editor en jefe, y un director técnico. El lector o la lectora de hoy que consulten los primeros números de la $R I$ encontrarán que la revista es plenamente reconocible en su formato, su estructura, sus explicaciones y justificaciones, y que la diferencia más llamativa es la publicación de editoriales en aquellos tiempos, práctica que desapareció con la llegada del argentino Alfredo A. Roggiano (1919-1991) en 1956. Por otra parte, desde el comienzo el IILI tuvo una organización cuidadosamente separada, con su propia mesa directiva, de la Revista Iberoamericana, con su comité editorial. También desde el comienzo hubo socios regulares o de número (\$4.00) y socios protectores que pagaban una suscripción anual mayor (\$10.00), además de suscripciones más favorables para socios residentes en América Latina; el lema del IILI permanece idéntico, “A la fraternidad por la cultura”, y el logo o colofón o sello oficial siguió igual hasta 1994, y sigue siendo reconocible en su versión actual. En las primeras décadas cada número llevaba una especie de epígrafe permanente (después llamado "Propósitos”) que rezaba:

Esta Revista aspira a constituir, gradualmente, una vital representación de los grandes valores espirituales de la creciente cultura iberoamericana.

\footnotetext{
${ }^{4}$ Últimamente hemos tenido conocimiento de un ensayo interesante escrito por Sebastiaan Faber, “'La hora ha llegado': Hispanism, Pan-Americanism and the Hope of Spanish/American Glory (1938-1948)”, el cual compara los primeros años de la RI con los de España Peregrina y Romance. ${ }^{5}$ Este afán de sistematización e institucionalización se materializa desde el comienzo con la preparación de An Outline History of Spanish American Literature (1942), An Anthology of Spanish American Literature (1946), y una serie de bibliografías pioneras; y el afán de canonización se transparenta en la publicación de la serie "Clásicos de América” y otras semejantes. También habría que recordar y reconocer el trabajo de Pedro Frank de Andrea, cuyas "Ediciones de Andrea" publicadas en la Ciudad de México estaban íntimamente vinculadas con el trabajo del IILI y la RI.
} 
Sus directores, así como el Instituto, quieren hacer vivo el lema que cifra el ideal de su obra: A LA FRATERNIDAD POR LA CULTURA.

Se reflejará en sus páginas una clara imagen del pensamiento de Iberoamérica.

En el período de Alfredo Roggiano la frase "Sus directores” se volvió “Su director y asesores”. Después de su muerte estos “propósitos” espirituales desaparecieron de la revista.

En aquel primer número publicado en 1939 se anunciaba :

El IILI es una organización integrada principalmente por intelectuales y catedráticos de literatura iberoamericana de ambas Américas, la anglosajona y la íbera. Como institución carece de biblioteca propia y de oficina permanente; lo mismo el personal de la mesa directiva que el de la comisión editora de la Revista, se renuevan en cada congreso.

En aquella época parecía evidente a los editores de la revista que la literatura era la expresión más alta de la cultura, pero también entendían que su función era estudiarla y propagarla desde el punto de vista del "pensamiento". A pesar de la época, seguían concibiendo su misión en términos espirituales y hablaban de sus actividades y de sus colegas con conceptos y epítetos que recordaban la era de Rodó y Darío antes que la de Franco, Hitler y Stalin:

A Costa Rica ha regresado Brenes Mesén, dejando en las universidades que utilizaron sus servicios una huella imborrable y luminosa de sabia y noble idealidad. Poeta de alto vuelo lírico, crítico de juicio recto y penetrante y filólogo de vasta reputación, Brenes Mesén no sólo ganó para sí en los Estados Unidos la estimación de sus colegas del magisterio, sino el amor respetuoso de sus muchos discípulos y la gratitud segura de cuantos amamos la cultura iberoamericana que a ellos explicó con fe de apóstol y autoridad de erudito. [Nro. 2, 1939, 481]

El que escribe es consciente de que la ironía de la mirada histórica sigue funcionando y nos espera en el camino. También en el nro. 2 se lanza una campaña para rendir homenaje al maestro colombiano Baldomero Sanín Cano y hay una lista estelar de los partidarios de dicha empresa que incluye un gran porcentaje de los intelectuales mejor conocidos de la época. En el nro. 3, Editorial II, “La hora de las Américas”, la revista declara, con acento de Rubén, que es importante que en el Nuevo Mundo, por lo menos, se intente "mantener a toda costa su fe en el Ideal" (13), a fin de "realizar para siempre el ensueño de las edades y hacer posible el reino del Espíritu entre los pueblos” (14). Esta nota idealista fue introducida particularmente por el nuevo editor en jefe Carlos García-Prada y reiterada más tarde por Arturo Torres-Rioseco; las contribuciones de Manuel Pedro González, Raimundo Lazo, Julio Jiménez Rueda y Francisco Monterde eran más sobrias y menos emocionales.

En el nro. 4 (noviembre 1940) se informa que en el II Congreso celebrado en Los Angeles entre "las instituciones que acogieron y agasajaron a los Congresistas con espléndidas señales de generosidad” estuvo “el Estudio de Walter Disney”(309). También se anuncia el lanzamiento de la "Biblioteca de Clásicos de América” con una Antología 
poética de González Prada ("el más brillante de los escritores peruanos de todos los tiempos”, 311). El nro. 13, noviembre 1943, 11-12, incluiría una lista extraordinariamente ambiciosa de lo que se planeaba, que nos recuerda empresas muy posteriores como la Biblioteca Ayacucho fundada por Ángel Rama en los años setenta o la Colección Archivos fundada por Amos Segala en los años ochenta del siglo pasado.

En un editorial sorprendentemente teleológico del no.10 (octubre 1942), "La Hora Panamericana", que transparenta las altas ambiciones culturales y políticas de algunos miembros del equipo editorial, Carlos García-Prada concibe las dos Américas como "el Hemisferio Central” del mundo que se estaba creando a través de la Segunda Guerra Mundial. Se podría concluir que hasta 1951 la RI tiene una doble intencionalidad, latinoamericanista y panamericanista a la vez (aunque el 95 por ciento de su contenido fue siempre latinoamericano), que, a partir de 1951, con la fundación de la Revista Interamericana de Bibliografía por la OEA, se vuelve redundante (si bien, en realidad, la mayoría de las empresas bibliográficas de la OEA/Unión Panamericana también quedaron truncas). En los próximos años, todavía con la Ciudad de México como centro de gravedad, la Revista pierde un poco su camino, hasta que en 1956 el IILI y la RI se trasladan a Estados Unidos (Iowa). En aquel momento, con Alfredo Roggiano como director (primero “técnico” y después “ejecutivo”), cesan los editoriales y las declaraciones de principios (remplazado, por un tiempo, por una sección muy sustancial dedicada a "Noticias de Hispanoamérica”) y la revista deviene latinoamericanista sin ambivalencias. Años más tarde, por otra parte, Alfredo Roggiano hablaría de vez en cuando de la "Hispanidad”, pero siempre de manera “ocasional” y sin demasiada convicción. La Revista fue siempre, y lo es todavía, una revista latinoamericana.

El III Congreso celebrado en Nueva Orléans en 1942 replanteó y ratificó una resolución aprobada en el primer congreso de México, 1938:

El Congreso manifiesta su más sincera simpatía por los gobiernos que respetan la libertad de pensamiento y el ejercicio libre de la cátedra, cualquiera que sea la posición filosófica o política de quienes ejercen la docencia en el aula o en el libro y reprueba la actitud de instituciones o gobiernos que han perseguido o separado de sus cátedras a hombres cuya única falta ha sido la de pensar y obrar con libertad.

El Congreso ratifica su posición democrática, afirmada en la primera Asamblea reunida en México, y hace votos por que todos los escritores de América comprendan, en toda su amplitud, el momento histórico por el que atraviesa la humanidad y tengan plena conciencia del destino que aguarda a nuestro continente y, en consecuencia, hagan de la libertad una bandera y de su pluma un arma para lograr que esos destinos se realicen plenamente y América sea tierra de libertad y de justicia, propicia para el florecimiento de la cultura. ${ }^{6}$

En aquel congreso Carlos García-Prada enfatizó la función única de la revista del IILI, primacía que es su orgullo hasta el día de hoy: "La Revista Iberoamericana es, entre todas las que se publican en el mundo, la única que está dedicada exclusivamente al estudio

\footnotetext{
${ }^{6}$ Citado por Julio Jiménez Rueda, “El Tercer Congreso y el destino de América”, $R I$ nro. 11, febrero 1943, 11-12.
} 
y difusión de las letras iberoamericanas". ${ }^{7}$ Por eso el nro. 16 (noviembre de 1944) fue dedicado a otro pionero, Joaquín García Monge, cuyo Repertorio Americano había llegado a sus 25 años y su número 1,000: “Grande y singular es la labor de García Monge, en estos tiempos de seco materialismo egoísta e indiferente ante las cosas del Espíritu” (7). En este número también se anuncia una nueva colección de traducciones literarias, the "Latin American Classics” (editada por John Englekirk y Angel Flores), una serie, paralela a los “Clásicos de América”, que sería publicada por la Universidad de Princeton con una lista de veinte títulos en primera instancia: "Las obras literarias más selectas de la América española y de la lusitana van a ser pronto vertidas al idioma de Shakespeare y de Whitman” (248). Es significativo ver que se desliza una especie de resentimiento por el nombre que los editores angloamericanos han escogido para su nueva colección: "Por necesidad de clasificación, el Instituto le ha dado el título de "Latin American Classics" a su nueva serie de publicaciones, pero bien podría haberle dado el de "Classics of America”, porque americanos son, y de los buenos, todos los autores que habrán de figurar en ella" (250-251).

En el nro. 19 (noviembre de 1945), el Presidente de turno, Arturo Torres-Rioseco, anuncia la dimisión de Carlos García-Prada y la elección de Julio Jiménez Rueda (“otro de los fundadores del Instituto”) como nuevo director de la revista. Previsiblemente, Torres-Rioseco alude al cargo de director de la revista como a un trabajo quijotesco en "esa zona espiritual en que todos debemos ceñir espada" (7).

En el no.20 (15 de marzo de 1946), en su primer editorial como director, Julio Jiménez Rueda, haciendo eco del editorial II, “La hora de América”, publicado por Carlos García-Prada (nro. 3), como también de su concepto de América como el futuro de la humanidad, escribe:

La antorcha que ha venido pasando de generación en generación desde el Oriente legendario a través de Grecia y de Roma, Francia, España, Portugal e Inglaterra, en un desplazamiento hacia el occidente del meridiano de la cultura, ha llegado a nuestro continente. (218-19)

\footnotetext{
${ }^{7}$ Los órganos más cercanos a la RI ("parientes políticos”, quizás, a pesar de los puntos de vista obviamente diferentes) son, sin duda, Cuadernos Hispanoamericanos (Ediciones Cultura Hispánica, Instituto de Cultura Hispánica/Instituto de Cooperación Iberoamericana, Madrid 1948-) y la Revista Interamericana de Bibliografía (OEA, Washington, 1951-). También parientes políticos en ultramar son la Revista de Filología Española (Madrid, 1914-, Menéndez Pidal) y la Revista de Occidente (Madrid, 1923-, Ortega y Gasset). Después vienen las revistas académicas fundadas por hispanistas extranjeros: Bulletin Hispanique (Bordeaux, 1898-), Hispania (Estados Unidos, 1917-), Bulletin of Hispanic Studies (Liverpool, 1923-), Hispanic Review (University of Pennsylvania, 1933-). De orientación diferente, desde luego, menos académicas y más literarias, son los primos hermanos, o revistas “americanas” y "americanistas": Repertorio Americano (San José de Costa Rica, 1919-1959, García Monge), Sur (Buenos Aires, 1931-1970, Victoria Ocampo), Marcha (Montevideo, 1939-1973, Quijano), Cuadernos Americanos, Ciudad de México, 1942-, Silva Herzog), Orígenes (1944-1956, Havana, Lezama Lima), Casa de las Américas (Havana, 1960-, Haydée Santamaría/Fernández Retamar).
} 
En el nro. 21 un editorial lamenta que “América pierde dos de sus grandes figuras intelectuales” (Antonio Caso y Pedro Henríquez Ureña); y en el nro. 22, de manera quizás sorprendente, se reproduce un discurso de Mariano Picón-Salas, “Apología de la pequeña nación”, sobre Puerto Rico (213-231). El nro. 23 es el primer "número especial” en la historia de la Revista, un "Homenaje a José Antonio Ramos (1885-1946)”, con contribuciones de Max Henríquez Ureña y Juan José Arrom, inter alios, y un largo artículo abiertamente marxista, por no decir comunista, de José Antonio Portuondo, "El contenido político y social de las obras de José Antonio Ramos (215-248). El próximo número especial, el nro. 26 (febrero de 1948), sería dedicado, finalmente, a Baldomero Sanín Cano, con estudios de Germán Arciniegas, Francisco Romero, Mariano Picón-Salas, Gabriela Mistral, José Antonio Portuondo, Juan Marinello, Max Henríquez Ureña, Jorge Mañach y Hernando Téllez, inter alios; con testimonios de Juana de Ibarbourou y Pedro Salinas.

A causa de la guerra, y de ciertos conflictos misteriosos entre los miembros del equipo editorial, pasaron siete años entre el tercer congreso y el cuarto. Quien vino a rescatar al Instituto fue el catedrático cubano Raimundo Lazo en 1949 al organizar un congreso en La Habana, explicando así su intervención: “Antes de que fuera posible preparar esta reunión necesariamente aplazada, el Prof. Torres-Rioseco se retiró de la presidencia del Instituto, aduciendo como razón la falta de cooperación para seguir desempeñándola. La renuncia del Presidente Torres-Rioseco agudizó la crisis que padecía la institución, en virtud de diversas causas explicables para todo el que conozca el mecanismo peculiar y el desamparo de esta clase de entidades privadas al servicio desinteresado de la cultura" (Memoria del Cuarto Congreso, v).

En el período 1950-1955 la Revista cambió poco y avanzó menos, aunque se ve más institucionalizada, más profesoral. A partir del nro. 36 (enero-septiembre 1953), el equipo editorial de la época (Julio Jiménez Rueda, Arturo Torres-Rioseco, Francisco Monterde, John E. Englekirk, Alberto R. Lopes, Manuel Pedro González, José Antonio Portuondo y John S. Brushwood) desaparece, remplazada por un triunvirato más compacto (los veteranos Julio Jiménez Rueda y Francisco Monterde, y el novato Fernando Alegría) lo cual sugiere que las tensiones entre González y Portuondo, por un lado, y Arturo TorresRioseco y quién sabe quiénes más, por el otro, habían llegado a un punto intolerable y a una inmolación colectiva de la mayor parte del equipo. Poco tiempo después, en el nro. 40 (abril-septiembre 1955) aparece el nombre de un tal Alfredo Roggiano reseñando a Luis Monguió, La poesía postmodernista peruana. Y en las actas del V Congreso celebrado en Berkeley en agosto de 1955, se lee que "el profesor Alfredo Roggiano propuso que la RI, órgano del Instituto, publique un número especial dedicado a comentar la obra del destacado humanista Pedro Henríquez Ureña, al cumplirse diez años de su muerte”. Ya para aquel entonces Roggiano, que hasta allí había sido profesor temporal en California, tenía un puesto en la State University of Iowa. Y en ese mismo congreso el delegado Raúl Silva Castro propuso: "El Instituto debe funcionar en un establecimiento de enseñanza superior que le acredite la independencia necesaria para la realización de sus fines ...”. El 23 de abril de 1956 el entonces Presidente del IILI, José Balseiro, de la University of Miami, escribió a la Mesa Directiva informándoles que la UNAM, cada vez más 
sobrecargada, ya no podía costear la producción e impresión de la Revista. Se proponía entonces que la University of Iowa alojara a la Revista —el IILI seguía en el limbo nomádico, viajando con el Presidente de turno, hasta 1963- y que el Director Técnico fuera Alfredo Roggiano, el nuevo profesor permanente de aquella universidad estadounidense.

Se llegó entonces al fin de la primera época de la Revista Iberoamericana. En su discurso inaugural dirigido al Décimo Quinto Congreso en Tucson, Arizona, en 1971, el ahora ex-presidente José A. Balseiro, quejándose de un mundo contemporáneo que era "infierno que consume a fuego lento la conciencia y la sensibilidad”, brindó una especie de epitafio de las primeras décadas y de los founding fathers de nuestras dos entidades:

Libres de los antagonismos doctrinarios entre los gobiernos, los miembros del IILI se dan las manos sobre las fronteras; $y$ forman un núcleo señero que comunica y justiprecia los mensajes espirituales de dos lenguas de las Letras del Nuevo Mundo. Porque si, individualmente, provenimos de tierras distantes y distintas, ampliadas o minúsculas, componemos una minoría homogénea animada por el ideal recíproco de escoger la flor de sus culturas.

Con sus medios limitados, humildísimos a veces, eso ha hecho, en algunas ocasiones, la pléyade representativa del Instituto. Al nacer, no hubiéramos podido predecir que padeceríamos años de languidez, cuando no de crisis. Porque abrió sus ojos en la región más transparente del aire: en aquel México generoso que siempre dijo "Presente" a cada hora en que sus afiliados acudieron a él (...).

Evoquemos a Julio Jiménez Rueda, seguro timonel de la primera aventura: a don Antonio Caso, clausurando el congreso con su fina autoridad; al inmortal Alfonso Reyes, solicitando, desde su retiro, que lo visitáramos con cuantos colegas quisiéramos llevar; al maestro de poetas que en todas las cosas buscaba un alma y un sentido oculto, a Enrique González Martínez, con los ojos nublados entonces, acercándose a la sesión inaugural para honrarla... Y para que no se piense que otros de mucho valer excusaban su preciosa colaboración, señalemos ahora, y aquí, a don Franciso Monterde, director de la Academia Mexicana de Letras y expresidente del Instituto. No ha faltado a ninguna de nuestras citas; y encargóse durante años, con Jiménez Rueda, de la publicación de la Revista Iberoamericana, sellándola con un disinterés personal y con la propiedad de su inteligencia. ¿Y cómo no destacar, asimismo, a Agustín Yáñez, quien sirvió como secretario de la Comisión de Investigaciones y Estudios Literarios para cuya presidencia tuve el privilegio de ser escogido, y quien años después, Gobernador de Jalisco, se lució en Guadalajara al favorecer con espléndida hospitalidad a este Instituto?

Fue así como México dio vida y se la ayudó siempre a mantener, a nuestro grupo, mediante la colaboración de figuras tan fieles al Instituto como la del hoy ausente, por dolorosa enfermedad, Arturo Torres-Rioseco. Y con aquel señorío adelantó México la imagen de los mejores congresos de esta asociación que, paradójicamente, y en general, han sido los celebrados en tierras ultrafronterizas, pese a que, para el primero, hace 33 años, el Presidente Roosevelt y su Secretario de Estado, Cordel Hull, manifestaron su interés al delegar en el ilustre hispanista Sturgis Leavitt y en nosotros como representantes de Estados Unidos. De una parte, en las universidades de esta nación se realizan investigaciones sobresalientes y se producen obras de egregia categoría en todos los campos del saber relacionados con la cultura iberoamericana, auspiciadas no pocas veces por principales Fundaciones. De la otra, la admirable aportación individual de sus scholars no siempre tuvo réplica adecuada en las escasas atenciones oficiales concedidas 
a reuniones como ésta. Más allá de nuestros linderos geográficos, los gobiernos nacionales elevaron a niveles de fiestas del intelecto y del espíritu la presencia de sus huéspedes. Diarios y revistas con pública responsabilidad e inquietudes intelectuales abrieron sus páginas a las voces más dignas de nuestra matrícula; y los amigos de la literatura y del bien decir se nos sumaron para escuchar las ponencias y los comentarios de carácter profesional. $^{8}$

\section{LA ÉPOCA DE RogGIANo 1955-1991}

Y ahora se registra el único lapso temporal en la accidentada historia de la Revista, ya que el nro. 40 lleva la fecha abril-septiembre 1955 y el nro. 41-42 corre de enero a diciembre de 1956, "patrocinada por la University of Iowa” y con una nueva división de responsabilidades. Ahora el Director Técnico es Alfredo Angel Roggiano, argentino (curiosamente los argentinos habían brillado por su ausencia en los primeros años del IILI), de la University of Iowa. Hay dos Directores Literarios para América Latina, Julio Jiménez Rueda y Francisco Monterde; y hay otro Director Literario para Estados Unidos, Fernando Alegría. Ya no hay “Editoriales” ni “Información” sino una sección de "Noticias importantes de Hispanoamérica”, sección que se convierte temporalmente en "Noticias de Hispanoamérica”, y después “Noticias de Iberoamérica”, para desaparecer completamente después del nro. 44 y ser reemplazada por una sección de “documentos” (literarios en vez de históricos). Ahora Roggiano ha sido redesignado "Director-Editor” y hay sólo un "Director Literario", Arturo Torres-Rioseco, ex-presidente del IILI radicado en Estados Unidos. Han desaparecido los directores literarios para América Latina radicados en América Latina; y se mantiene un “Secretario Ejecutivo-Tesorero” (designación que había existido desde 1953), Marshall Nason, de la University of New Mexico, obviamente como contrabalanza al poder de Roggiano sobre la Revista. Sólo en 1963 se consolidarán Director y Secretario Tesorero en el mismo lugar.

Ha pasado, entonces, una cosa muy curiosa y quizás significativa. En el momento en que la Revista se afianza en forma permanente a una institución académica de Estados Unidos, deja de comentar asuntos no literarios, se distancia en ciertos aspectos del Instituto del cual es “órgano” — ya que deja de registrar la mayoría de sus actividadesy se vuelve más estrechamente académica. Y esta ligera objetivación y separación es llevada a cabo por un director en quien se fusionarán eventualmente (y paradójicamente), la dirección de la revista y la del instituto. Mucha administración, poca política. Ya no más discusiones de latinoamericanismo, iberoamericanismo, panamericanismo, hispanismo, etc. Sería erróneo pensar, sin embargo, que aquel silencio político y administrativo de Roggiano, aquella aparente modestia, significase una ausencia de "política" en la administración ideológica y administrativa de la Revista. Lo que consiguió con la concentración de poderes y la supresión de polémicas extraliterarias fue la estabilización institucional y académica de las dos entidades después de diecisiete años de inseguridad económica y geográfica, de pugnas y facciones ideológicas y personales. Que haya logrado ser reelegido regularmente en las asambleas a lo largo de un período de treinta y cinco

${ }^{8}$ Memoria del XV Congreso (Universidad de Arizona, 1974), 11-13. 
años, durante una época ideológica muchísimo más conflictiva y complicada, demuestra la solidez de sus criterios y el reconocimiento de esa solidez en la percepción de sus colegas y los socios. (Sólo a partir de 1984 empezaría Roggiano a comentar, de vez en cuando, la política académica e ideológica de la Revista, y la contribución personal a su trayectoria). También demuestra otra verdad igualmente sorprendente. La complicada estructura del Instituto y la complejidad de sus relaciones con sus socios y la Revista, por no hablar de América Latina y Estados Unidos, deberían haber augurado, a primera vista, una vida muy turbulenta y corta para las dos entidades. Y por el contrario, el IILI ha sobrevivido sesenta y cuatro años y la Revista ha llegado a 200 números y más de 50,000 páginas, quizás precisamente porque sus estructuras — es decir, la concepción original— correspondían a las intrincadas realidades y exigencias que eran llamadas a confrontar y satisfacer.

Lentamente la Revista cambia. Son los años sesenta. De los escritores que serán los más estudiados a finales de aquella década crucial, sólo Borges ha aparecido en las páginas de la revista durante los años cincuenta. Con todos los cambios que se pueden notar, los gustos del RI durante la época de Roggiano se parecerán siempre más a los de Sur que a los de Cuadernos Americanos. Será una revista identificada más con "Borges y Cortázar y el Cono Sur”, por ejemplo, que con “Asturias, Fuentes, García Márquez, Cuba y Centroamérica”. Pero estamos hablando de tendencias y relatividades: en sus páginas aparecen casi todos los escritores latinoamericanos importantes y casi todos los críticos latinoamericanistas influyentes de los últimos sesenta años; no podría haber mayor y mejor justificación de la existencia de una revista.

El nro. 41-42 (enero-diciembre 1956), el primero editado por Roggiano, es un homenaje espectacular a su maestro Pedro Henríquez Ureña. En el nro. 46 (juliodiciembre 1958) hay una “Evocación y aprecio de Ricardo Rojas”. Pero en diez años las cosas cambian: el nro. 62 (julio-diciembre 1966), incluye artículos sobre Cortázar y Guimarães Rosa; el nro. 63 (enero-junio 1967) incluye a Cortázar, Carpentier y Roa Bastos; el nro. 65 (enero-abril 1968), a Borges, Roa Bastos, Cortázar, Vargas Llosa y Sábato. El nro. 64 (julio-diciembre 1967) es un homenaje a Rubén Darío, con la primera cubierta ilustrada, una introducción y un poema realizados por Jorge Guillén. El nro. 65 (enero-abril 1968) también está ilustrado con fotos de Jorge Luis Borges aunque, curiosamente, no hay nada sobre él entre las cubiertas. El nro. 67 (enero-abril 1969) es un número especial sobre Miguel Ángel Asturias, quien acaba de ganar el primer Premio Nobel otorgado a un novelista latinoamericano. Se inaugura con un ensayo de Emir Rodríguez Monegal, vocero extraoficial del Boom, quien, después de su experiencia turbulenta con Mundo Nuevo en París, busca aguas más tranquilas en la academia norteamericana y aparecerá por primera vez en la Comisión Editorial de la Revista en el no.69 (septiembre-diciembre 1969); seguirá en ella hasta 1977. Entre otros, Rodríguez Monegal editará el nro. 76-77 (julio-diciembre 1971), “La última década de la literatura hispanoamericana”, que incluye su propio ensayo, "Una escritura revolucionaria”, sobre el Boom. (Es irónico constatar que uno de los que se oponen con más vehemencia al Boom durante esta época es Manuel Pedro González, fundador del IILI pero más cerca, en estos tiempos, de Casa de las Américas que de la Revista Iberoamericana). Desde 1969 en adelante la $R I$ se publicará, "normalmente”, cuatro veces al año. 
Mientras tanto, España empieza a darse cuenta del nuevo mundo latinoamericano que se está augurando y en 1975 el IILI visita la Península (y Europa) por primera vez. Quizá un poco ingenuamente, Francisco Sánchez-Castañer, Presidente del Congreso de Madrid en 1975, comenta en su discurso inaugural: “Aunque parezca mentira, desde 1938, año de la primera reunión en Méjico, nunca había sido el viejo solar español el lugar escogido para los congresos periódicos organizados por el IILI”. La relación entre el IILI, la Revista y el exilio (por no decir el nomadismo) es un tema de mucho interés que no se ha estudiado todavía.

Llega el nro. 100 —más bien, 100-101— de la Revista en 1977. No se publica un número conmemorativo, aunque sí se publica un número muy “especial”, “40 Inquisiciones sobre Borges”. Muchos pensarán que los próximos seis o siete años podrían ser considerados una de las épocas doradas de la Revista (ver sumarios, números especiales, autores, etc.). En el nro. 146-147 (enero a junio de 1989) puede advertirse que un mundo se acaba y otro empieza: se pide a los autores enviar sus trabajos "en disquette de 3.5" compatible con Microsoft Word o de 5.25" compatible con IBM-Word Perfect”. Alfredo Roggiano es ahora "Director Ejecutivo y de Publicaciones" (1986-92). El trabajo — cuatro números de la revista al año, a veces dos congresos al año- es abrumador; y finalmente, a fines de los años ochenta, las décadas empiezan a pesar y el Director Ejecutivo se enferma. Alfredo A. Roggiano muere el 26 de octubre de 1991, a pocos meses del año más simbólico de la historia de su querida "Iberoamérica”. Es remplazado temporalmente por su colega de Pittsburgh, el secretario tesorero Keith McDuffie, hasta que los Estatutos del IILI se revisan (1994-95) y se inicia una nueva época en la trayectoria del IILI y su órgano literario.

El colaborador más importante - decisivo, incluso- de Roggiano había sido Rodríguez Monegal, aunque, curiosamente, pocos parecen darse cuenta de ello. El crítico uruguayo falleció en 1986 pero dos años antes de su muerte, en su diario del XXIII Congreso del IILI celebrado por segunda vez en Madrid, nos dejó por anticipado quizás el mejor epitafio del director ejecutivo al que más se identifica con el IILI en el recuerdo de los socios:

Tal vez convenga aclarar, antes de ir más adelante, que el formidable título de Director Ejecutivo, no es mera hipérbole burocrática. Hay pocas personas en el mundo iberoamericano a quienes el adjetivo caiga tan bien. Porque además de poeta, profesor, crítico y erudito, Roggiano es uno de los más importantes, sino el más importante de los directores ejecutivos de nuestra cultura en su ámbito internacional. Su afiliacion con el Instituto (creado en México, 1938, por una asociación internacional de profesores de literatura iberoamericana) data de 1955 . A partir de esa fecha, Roggiano se hace cargo de la Revista Iberoamerica, órgano del Instituto. Antes del 55, la Revista era decorosa y aburrida. A partir de su jefatura, y en proceso lento pero seguro de actualización, adquirió un cáracter no sólo ecuménico sino verdaderamente internacional. Sus colaboradores dejaron de ser sólo hispanistas, más o menos vinculados a universidades norteamericanas, sino representantes de todas partes del mundo iberoamericano. No hay en el vasto y laberíntico campo de la crítica de nuestra literatura una revista que esté tan al día. [...] Ninguna ofrece un panorama de las distintas escuelas y tendencias que han ocupado nuestro diálogo crítico con la precisión e imparcialidad de la Revista Iberoamericana. 
Las fantasías de la mudable estrategia política iberoamericana no la han afectado. La Revista ha dedicado números monográficos a tirios y a troyanos, tanto a Neruda y Arguedas como a Borges y a Darío. En los casi treinta años que ya corren desde que Roggiano se hizo cargo de la misma, nuestra crítica ha padecido varios sarampiones: a los restos del positivismo que orientaba a muchos de los fundadores sucedió la muy filológica estilística, el truculento existencialismo a la francesa, el sociologismo primario de los marxistas, la nueva crítica norteamericana, el formalismo revisitado por los estructuralistas, y ahora la desconstrucción (que había anticipado Borges en su "Pierre Menard"). Cada una de esas "novedades" ha encontrado acogida imparcial en las páginas de la Revista, sin que se puede decir que las predilecciones personales del Director (que las tiene y son muy identificables en el campo de la crítica) hayan inclinado la balanza en un sentido o en otro.

La formación intelectual de Roggiano se apoya sólidamente en sus años de estudio en la Argentina, inspirado por maestros como el español Amado Alonso (fundador del Instituto de Filología de Buenos Aires) y, sobre todo, del crítico dominicano Pedro Henríquez Ureña, a quien dedicó el primer número a su cargo de la Revista (41-42, 1956). A esto hay que agregar su larga experiencia de profesor universitario en varios centros de estudio de Estados Unidos, y especialmente en Pittsburgh (donde fue recientemente nombrado profesor distinguido). Esta experiencia y esta trayectoria le han permitido mantener con mano firme la dirección de la Revista. No menos firme ha sido su organización de los congresos internacionales del Instituto. En vez de confinarse al área norteamericana o al de los países vecinos, como se hacía antes de su gestión, Roggiano ha llevado al Instituto a Lima (1973), a Madrid (ya en 1975), a Río de Janeiro (1977), a Budapest (1978), a Caracas (1979), a París (1983), y ahora nuevamente a Madrid. ${ }^{9}$

\section{LA ÉPOCA ACTUAL DESDE 1992}

Nos vamos a limitar a un breve resumen de la época reciente. Entre 1993 y 1996 hubo una especie de transición o relevo entre el heredero inmediato de Roggiano, Keith McDuffie, veterano del IILI, y la estudiosa uruguaya Mabel Moraña, elegida Directora de Publicaciones en 1996 tras la revisión de los Estatutos del IILI. A partir de entonces se efectua la plena democratización de este Instituto y la profesionalización de sus políticas editoriales. La Revista Iberoamericana se ha convertido en un refereed journal, donde los artículos se evalúan anónimamente por al menos dos asesores literarios en las distintas especialidades contempladas por la nueva estructura de la Comisión Editorial. Los socios del IILI han respondido de la manera más positiva a ese cambio sustancial en la política de evaluaciones, entendiendo que dicho procedimiento favorece el prestigio de sus publicaciones. También se ha incorporado un Director de Reseñas, Daniel Balderston,

\footnotetext{
${ }^{9}$ Rodríguez Monegal, “Iberoamérica a la España nueva”. Véase también José Miguel Oviedo, "Iberoamérica: encuentro en Madrid", Revista de la Universidad de México, pp.48-52 (también sobre el XXXIII Congreso de Madrid); Emir Rodríguez Monegal, “Diario de Caracas”, Mundo Nuevo nro. 17, París, noviembre 1967, 4-19 (reproducido en este número); y Emir Rodríguez Monegal, "Diario de la Unesco", Revista de la Universidad de México, 28, 1983, 44-52, sobre el XXII Congreso, París, 1983.
} 
renovando y mejorando radicalmente el procesamiento de tan importante actividad profesional y académica.

Intelectualmente, la nueva directora se enfrentaba con una situación global post-1989 y post-1992 igualmente o más significativa que la época en que el IILI y la RI fueron fundados. Ya era hora también de que la Revista asimilara los cambios radicales que se habían registrado en los estudios literarios latinoamericanos en los años precedentes, cambios que el mismo Roggiano, dada su edad y sus inclinaciones generacionales, no estaba en condiciones de asimilar y propagar. Los lectores pueden juzgar con qué amplitud de criterios y con cuánta energía la primera mujer directora de la Revista ha emprendido su tarea. Se han discontinuado los “volúmenes nacionales” y en su lugar se han publicado diferentes números especiales que se alternan con los regulares, lo cual permite avanzar nuevos temas (los estudios culturales, por ejemplo) dentro de los intereses del IILI y acercar nuevos socios y contribuyentes de otras áreas del latinoamericanismo.

Se ha impulsado una notable expansión de las líneas de publicaciones, la cual recuerda la actividad pionera de los primeros años del Instituto. Se han sumado a los cuatro números anuales de la Revista Iberoamericana las siguientes series: a) Críticas, destinada a la relectura y actualización de críticos latinoamericanos cuya obra se vincula a los estudios en este campo (hasta ahora se han publicado volúmenes sobre Ángel Rama, Roberto Fernández Retamar, Antonio Candido y Antonio Cornejo Polar); b) Nuevo Siglo, dedicada a obras monográficas de un solo autor (hasta ahora se han publicado Saberes americanos: subalternidad y epistemología en los escritos de Sor Juana de Yolanda Martínez San Miguel y Al sur de la modernidad. Comunicación, globalización y multiculturalidad de Jesús Martín Barbero); c) la Serie ACP (logo referido al nombre de Antonio Cornejo Polar, distinguido ex-presidente del Instituto), que representa, de alguna manera, la continuación y adaptación de la serie “Clásicos de América” iniciada hace seis décadas, y que publicará libros colectivos sobre autores canónicos latinoamericanos (en preparación: un libro sobre Nicolás Guillén, coordinado por Jerome Branche, y otro sobre Ricardo Piglia); d) continuación y renovación de la serie Tres Ríos para la publicación de trabajos presentados en congresos; e) Biblioteca de América, volúmenes colectivos sobre temas críticos variados (hasta ahora se ha publicado Mujer y cultura en la Colonia hispanoamericana, ed. Mabel Moraña; Indigenismo hacia el fin del milenio. Homenaje a Antonio Cornejo Polar, ed. Mabel Moraña; Sexualidad y nación, ed. Daniel Balderston; Agencias criollas. La ambigüedad colonial en las letras hispanoamericanas, ed. José Antonio Mazzotti; y está en prensa Heterotropías: narrativas de identidad y alteridad latinoamericanas, ed. Carlos Jáuregui y Juan Pablo Dabove).

Con esta dirección dinamizada, la vitalidad de nuestras dos instituciones se ha consolidado y el IILI tiene actualmente el mayor número de socios y la Revista el mayor número de suscriptores de toda su historia. En julio del 2002 el XXXIV Congreso se celebrará en Iowa, universidad estrechamente identificada con la historia de las dos entidades. No es fácil ser especialmente optimistas a corto plazo con respecto a la evolución de la actual coyuntura política y económica del panorama internacional pero, en cuanto a nuestras actividades culturales, me complace pensar que de aquí a treinta y seis años los socios del IILI estarán conmemorando su centenario y ya estarán pensando en el número 350 de la Revista Iberoamericana. 